\title{
Association between Gastric Pathology and Hepatitis B Virus Infection in Patients with or without Helicobacter Pylori
}

\author{
Mahmud Baghbanian', Seyyed Abolfazl Hoseini Mousa ${ }^{1 *}$, Masoud Doosti ${ }^{2,3}$, \\ Mansour Moghimi ${ }^{4}$
}

\begin{abstract}
Background: In the recent years, hepatitis B virus (HBV) infection has been considered as a risk factor for gastric cancer, but further studies are required to confirm these claim. The present study was aimed to evaluate the correlation between gastric pathology (precancerous and cancerous conditions) with HBV infection in Helicobacter pylori (H. pylori) positive or negative patients. Methods: In this cross-sectional study, 728 patients under endoscopy examination in Yazd Shaheed Sadoughi Hospital between 2017 and 2018 were participated. Histopathological analysis was performed on gastric specimens. Hepatitis B surface antigen (HBsAg) in sera was detected by the enzyme-linked immunosorbent assay (ELISA). The relationship between gastric pathology and HBV infection were explored by logistic regression analysis. Results: Of 728 patients, HBsAg and H. pylori infection were detected in 83 and 408 patients, respectively. Sixty nine patients were co-infected with $H$. pylori/HBV. H. pylori infection detected in patients with HbsAg positive significantly more than those were negative for $\mathrm{HbsAg}(\mathrm{p}=0.029)$. None of $\mathrm{HBV} / \mathrm{H}$. pylori co-infected patients did not have normal gastric tissue. A significant difference was seen in histopathology of gastric tissue between HBsAg positive patients with and without $H$. pylori infection $(\mathrm{p}<0.0001)$. The HBsAg was associated with histopathology of gastric $(\mathrm{OR}=21.56$, $95 \% \mathrm{CI}=7.070-65.741, \mathrm{p}<0.001)$ and as a risk factor for gastritis $(\mathrm{OR}=12.457,95 \% \mathrm{CI}=3.007-51.614, \mathrm{P}=0.001)$ but no cancer $(\mathrm{OR}=2.127,95 \% \mathrm{CI}=0.242-18.704, \mathrm{P}=0.496)$. Conclusion: The HBV infection alone is associated with some precancerous lesions but is not correlated with gastric cancer. It can increase development of premalignant conditions and carcinoma significantly in $H$. pylori positive patients.
\end{abstract}

Keywords: Gastric cancer- Hepatitis B virus- Helicobacter pylori

Asian Pac J Cancer Prev, 20 (7), 2177-2180

\section{Introduction}

The gastric cancer is the fourth most commonly diagnosed cancer in men and fifth in women worldwide. A decrease in the incidence rate of gastric cancer has shown in developed countries during recent decades, but the mortality rate associated with this malignancy is still high (Ge et al., 2018). The incidence rate of this cancer in Iran is 158 cases per 100,000 peoples. A cascade of pathology changes, including non-atrophic gastritis, atrophic gastritis, intestinal metaplasia, and dysplasia happens to finally create stomach carcinoma (Mera et al., 2018). Some infectious agents can affect gastric tissue (Fattahi et al., 2018). Helicobacter pylori (H. pylori) is the most common risk factor for changing of normal gastric tissue to cancer (Mera et al., 2018). The association of Epstein-Barr virus (EBV) and cytomegalovirus (CMV) infection with stomach cancer is controversial (Fattahi et al., 2018; Varga et al., 2018). Other risk factors include genetic factors, family history, smoking, diabetes and alcohol drinking (Lochhead and El-Omar, 2018).

Hepatitis B virus (HBV) is a DNA virus that has liver tropism. It can induce hepatic damage and subsequent hepatocellular carcinoma (Ahmadi Vasmehjani et al., 2015). Chronic HBV infection is associated with extra-hepatic cancers (EHCs) such as, pancreatic cancer, non-Hodgkin's lymphoma and gastric cancer. HBV may infect non-hepatic tissues through the bloodstream and its antigens can be detected in non-liver organs such as stomach, gastrointestinal tract, pancreas and kidney. It is possible that hepatitis B virus replicates within extra-hepatic tissues and plays an oncogenic role (An et al., 2018).

In recent years, researchers have found an association between hepatitis B surface antigen (HBsAg) and stomach cancer. Chen et al., (2004) were found HBsAg and $\mathrm{HBcAg}$ of hebatitis $\mathrm{B}$ virus in the gastric mucosa of patients infected with $H$. pylori. They were not observed 
a significant difference in the expression level of HBV antigen between the $H$. pylori positive and negative patients. It was also reported that the high prevalence of gastric malignancy was linked to liver cirrhosis caused by HBV virus. Wei et al., (2015) were found that HBV was potentially associated with stomach cancer. In a study conducted in Iran, HBV was not associated with gastric malignancy (Ghasemi et al., 2012).

The majority of studies are conducted in China, where both HBV infection and gastric cancer are endemic. Therefore, it is required that the association between HBV and gastric cancer clear by further studies in the other region of the world. In addition, up to date, the correlation of HBV and precancerous lesions of the stomach has not been clearly elucidated. The present study was aimed to evaluate an association between gastric pathology with hepatitis B virus infection in patients with or without helicobacter pylori.

\section{Materials and Methods}

\section{Study population}

This cross-sectional study performed on 728 patients under endoscopy examination who referred to Yazd Shaheed Sadoughi Hospital between 2017 and 2018. A gastric biopsy and serum sample was taken from each patient. All subjects signed an informed consent form before sample collection. Exclusion criteria were the following: age under 18 years old, the impossibility for perform endoscopy, and difficulty of taking a stomach biopsy. Patient demographic characteristics, including, age, sex, type of digestive disorder, and the history of drug addiction were collected by a questionnaire. The study was approved by the Ethics Committee of Shahid Sadoughi University of Medical Sciences in Yazd (IR. SSU.MEDICINE.REC.1396.263).

\section{Pathological analysis of gastric specimens}

Tissue samples were fixed in $10 \%$ formalin, sliced into smaller sections, and then embedded in paraffin. The paraffin-embedded tissues were cut into five micron segments and stained with hematoxylin-eosin ( $\mathrm{H}$ and $\mathrm{E}$ ) and Giemsa for histopathological evaluation of the tissues and detection of $H$. pylori infection. The histological feature of samples and the pathological stage of tissues were estimated by two pathologists according to the American Joint Committee on Cancer criteria.

\section{Serologic assay for detection of HBV infection}

Hepatitis B surface antigen (HBsAg) in serum was detected by the enzyme-linked immunosorbent assay (ELISA) technique according to the manufacturer's instruction (Diapro, Italy) with high sensitivity (100\%) and specificity $(99.5 \%)$.

\section{Statistical analysis}

Data were analyzed using SPSS 21.0 statistical software (SPSS Inc., Chicago, IL, USA). Comparison of variables between $\mathrm{HBsAg}$ positive and negative groups were carried out by Chi-square and test. Logistic regression analysis was performed to determine the association between histopathology of gastric and HBsAg positivity. A P-value less than 0.05 was considered statistically significant.

\section{Results}

Of 728 patients under study, 370 people (50.8\%) were male and 358 (49.2\%) female. Frequency distribution of population in terms of variables under study is summarized in Table 1. Twenty three patients were addicted and 83 subjects (11.4\%) were HBsAg positive. H. pylori infection was detected in 408 patients $(56 \%)$ and 69 peoples were also co-infected with $H$. pylori/HBV.

According to histopathology of gastric, patients were placed in six groups, including, normal, gastritis, atrophic gastritis, metaplasia, dysplasia and cancer. In 259 subjects (35.6\%), histopathology of stomach was normal. Dysplasia had the lowest frequency, while Gastritis was the most common histopathological phenotype (40.1\%) and gastric cancer detected in 35 cases (4.8\%).

Table 2 shows the association between variables under study and HBsAg detection. A significant association between the mean age $(p=0.043)$, sex $(p=0.01)$, addiction $(\mathrm{p}=0.031)$ and $\mathrm{Hbs} \mathrm{Ag}$ positivity was observed. In addition, $H$. pylori infection detected in patients with $\mathrm{HbsAg}$ positive significantly more than those were negative for $\operatorname{HbsAg}(\mathrm{p}=0.029$, Table 2).

Histopathology findings between $\mathrm{HBsAg}$ positive and HBsAg negative patients are compared and summarized in Table 3. None of HBV/H. pylori co-infected patients

Table 1. Frequency Distribution of Population in Terms of Variables under Study

\begin{tabular}{lcc}
\hline Characteristic & $\mathrm{n}$ & Percentage \\
\hline Sex & 370 & 50.8 \\
$\quad$ Male & 358 & 49.2 \\
$\quad$ Female & & \\
Addiction & 23 & 3.2 \\
$\quad$ Yes & 705 & 96.8 \\
$\quad$ No & & \\
HBV infection & 83 & 7.57 \\
HBsAg positive & 645 & 92.43 \\
HBsAg negative & & \\
H. pylori infection & 408 & 56 \\
Positive & 320 & 44 \\
Negative & & \\
HBV/H. pylori co-infection & 69 & 9.4 \\
$\quad$ Yes & 659 & 90.6 \\
No & & \\
Histopathology of gastric & 259 & 35.6 \\
Normal & 292 & 40.1 \\
Gastritis & 60 & 8.2 \\
Atrophic gastritis & 63 & 8.7 \\
Metaplasia & 19 & 2.6 \\
Dysplasia & 35 & 4.8 \\
Cancer & & \\
\hline
\end{tabular}


Table 2. Association between Some Variables under Study with HBsAg Positivity

\begin{tabular}{lccc}
\hline Variable & $\begin{array}{c}\text { HbsAg } \\
\text { positive }\end{array}$ & $\begin{array}{c}\text { HbsAg } \\
\text { negative }\end{array}$ & P value \\
\hline Mean age & $53.63 \pm 14.40$ & $42.70 \pm 12.62$ & 0.043 \\
Sex & & & \\
$\quad$ Male & $56(67.5 \%)$ & $314(48.7 \%)$ & 0.001 \\
$\quad$ Female & $27(32.5 \%)$ & $331(51.3 \%)$ & \\
Addiction & & & \\
$\quad$ Yes & $11(13.3 \%)$ & $12(1.98 \%)$ & 0.031 \\
$\quad$ No & $72(86.7 \%)$ & $633(98.02 \%)$ & \\
H. pylori infection & & & \\
$\quad$ Positive & $69(83.1 \%)$ & $339(52.6)$ & 0.029 \\
$\quad$ Negative & $14(16.9 \%)$ & $306(47.4 \%)$ & \\
\hline
\end{tabular}

did not have normal gastric tissue and gastritis was the most frequently histological finding in them. The majority of HBsAg positive/H. pylori negative patients had atrophic gastritis. There is a significant difference in histopathology of gastric tissue between $\mathrm{HBsAg}$ positive patients with and without $H$. pylori infection $(\mathrm{p}<0.0001$, Table 3). Fifty five HBsAg negative/ H. pylori positive patients had normal gastric tissue. H. pylori infection was significantly associated with gastric cancer either in patients with or without HBV infection. Precancerous conditions and cases of gastric cancer in $H$. pylori positive patients were founded to be more than patients without $H$. pylori infection. Logistic regression analyses showed that the presence of HBsAg is associated with histopathology of gastric (Table 4, OR=21.56, 95\% $\mathrm{CI}=7.070-65.741$, $\mathrm{p}<0.001)$. The HBsAg was as a risk factor for gastritis $(\mathrm{OR}=12.457,95 \% \mathrm{CI}=3.007-51.614, \mathrm{P}=0.001)$ but no cancer $(\mathrm{OR}=2.127,95 \% \mathrm{CI}=0.242-18.704, \mathrm{P}=0.496)$.

\section{Discussion}

Recent studies have reported hepatitis B virus infection associated with gastric mucosal lesions and stomach carcinoma. Results of the present study showed that HBV infection is significantly linked to increasing risk of developing precancerous conditions but no gastric cancer. The role of Helicobacter in the development of gastric cancer was more intense than the hepatitis B virus. The results of the present study introduce $\mathrm{HBV}$ as a possible risk factor or cofactor for gastric carcinoma only in coinfection with $H$. pylori.

Many previous studies have obtained a positive strong relationship between Helicobacter pylori infection and gastric lesions, so that the World Health Organization considered this bacterium as a class 1 carcinogen for gastric cancer (Wang et al., 2016). The role of HBV infection in the development of hepatocellular carcinoma is confirmed by previous studies, but limited reports have shown an association between this virus with other malignancies such as renal cancer and gastric cancer (Ghasemi et al., 2012). Malignancy is a multifactor disease and $\mathrm{HBV}$ infection is a risk factor for liver cirrhosis and hepatocellular carcinoma (Hosseini et al., 2011). Several studies introduced liver cirrhosis as a risk factor for gastric cancer (Zullo et al., 2003; Kirchner et al., 2011). Therefore, HBV infection and gastric cancer may be linked by liver cirrhosis. On the other hand, HBsAg is detected in gastric epithelial cells (Chen et al., 2004; Wei et al., 2015), thus it is possible that HBV directly increases the risk of gastric cancer. Stomach is adjacent to liver and may be infected by HBV. In the current study, HBsAg was detected in $11.4 \%$ of patients suffering from gastric cancer. In a study conducted in China, the existence of HBsAg in ten common extra-hepatic cancers was evaluated. About $14 \%$ of patients with gastric cancer were $\mathrm{HBsAg}$ positive (Lu et al., 2018). In Republic of Korea, HBsAg was positive in $4.7 \%$ of men and $3.4 \%$ of women with stomach cancer (An et al., 2018).

In the present study, cases of precancerous and gastric cancer in $\mathrm{HBV} / H$.pylori co-infected patients were significantly more than $H$. pylori positive/HBV negative

Table 3. Comparison of Histopathology Findings between HBsAg Positive and HBsAg Negative Patients

\begin{tabular}{lccccccccc}
\hline HBV infection & $\begin{array}{l}\text { H. pylori } \\
\text { infection }\end{array}$ & Normal & gastritis & Atrophic gastritis & Metaplasia & Dysplasia & Cancer & total & P value \\
& & 0 & $28(3.8)$ & $14(1.9)$ & $10(1.3)$ & $5(0.6)$ & $8(1)$ & $69(9)$ & $<0.0001$ \\
HBsAg positive & Positive & 0 & $6(0.5)$ & $6(0.8)$ & $2(0.2)$ & 0 & $1(0.1)$ & $14(1.9)$ & \\
& Negative & $5(0.6)$ & $4(5)$ & $40(5.4)$ & $42(5.7)$ & $10(1.3)$ & $20(2.7)$ & $339(46.5)$ & 0.003 \\
HBsAg negative & Positive & $55(7.5)$ & $255(35)$ & 0 & $9(1.2)$ & $4(0.5)$ & $6(0.8)$ & $223(42)$ & \\
& Negative & $199(27.3)$ & $5(0.6)$ & 0 & & & & &
\end{tabular}

Table 4. Association between Histopathology of Gastric and HBsAg Positivity in Logistic Regression Analyse

\begin{tabular}{lccccc}
\hline Histopathology of gastric & $\begin{array}{c}\text { HBsAg positive/ H. pylori } \\
\text { negative }(\mathrm{n}=18)\end{array}$ & $\begin{array}{c}\text { HBsAg/H. pylori } \\
\text { negative }(\mathrm{n}=223)\end{array}$ & OR & 95\% CI & P value \\
\hline Gastritis & 4 & 5 & 12.457 & $3.007-51.614$ & 0.001 \\
Atrophic gastritis & 6 & 0 & 8.077 & - & 0.994 \\
Metaplasia & 2 & 9 & 2.972 & $0.592-14.932$ & 0.1868 \\
Dysplasia & 0 & 4 & 0 & 0 & 0.999 \\
Cancer & 1 & 6 & 2.127 & $0.242-18.704$ & 0.496 \\
Total & 13 & 24 & 21.56 & $7.070-65.741$ & $<0.001$ \\
\hline
\end{tabular}


patients (Table $3, \mathrm{p}<0.0001$ ). This finding shows that HBV infection may contribute in progression of gastric cancer. Unlike the findings of the current study, some previous studies have not founded a link between $H$. pylori and HBV infection in gastric lesions. Chen et al., (2004) were detected $\mathrm{HBsAg}$ and $\mathrm{HBcAg}$ in the gastric mucosa infected with $H$. pylori, but they were not obtained a significant difference in expression of HBsAg between the $H$. pylori-positive and -negative gastric tissues in HBV-infected patients.

In the current study, only one patients with gastric cancer was HBsAg positive/H. pylori negative; therefore, the role of hepatitis B infection alone and directly in the development of stomach cancer is not strong (Table 4, $\mathrm{OR}=2.127,95 \% \mathrm{CI}=0.242-18.704, \mathrm{P}=0.496)$. Unlike this finding, Wei et al., (2015) were reported a positive association between HBV infection and gastric cancer in a case-control study. They did not evaluate the subjects for Helicobacter pylori infection, thus may be infection with $H$. pylori has been effective in them results. In a study conducted in north of Iran, HBV was not associated with gastric malignancy because viral DNA was undetectable in all one hundred samples (Ghasemi et al., 2012). We were not performed the PCR for detecting viral genome and it was a limitation for this study. Based on literature review, the HBV genome is detected in less than $5 \%$ of gastric cancer tissues (Chen et al., 2015); therefore, further research with large sample size is needed to confirm the relation between this virus and gastric carcinoma.

In conclusion, this study showed that HBV infection alone is associated with some precancerous lesions but is not correlated with gastric cancer. HBV can increase development of premalignant conditions and carcinoma significantly in patients infected with $H$. pylori.

\section{Acknowledgements}

This research was part of a doctoral thesis supported by Yazd Shahid Sadoughi University of Medical Sciences

\section{Conflict of interest}

The authors declare that they have no conflict of interest.

\section{References}

Ahmadi Vasmehjani A, Javeshghani D, Baharlou R, et al (2015). Hepatitis A infection in patients with chronic viral liver disease: a cross-sectional study in Jahrom, Iran. Epidemiol Infect, 143, 534-9.

An J, Kim JW, Shim JH, et al (2018). Chronic hepatitis B infection and non-hepatocellular cancers: A hospital registry-based, case-control study. PLoS One, 13, e0193232.

Chen NL, Bai L, Deng T, et al (2004). Expression of hepatitis $\mathrm{B}$ virus antigen and Helicobacter pylori infection in gastric mucosa of patients with chronic liver disease. Hepatobiliary Pancreat Dis Int, 3, 223-5.

Chen XZ, Wang R, Hu JK (2015). Hepatitis B virus infection and gastric cancer risk: pitfalls in the potential association. Br J Cancer, 112, 1844.

Fattahi S, Nikbakhsh N, Taheri H, et al (2018). Prevalence of multiple infections and the risk of gastric adenocarcinoma development at earlier age. Diagn Microbiol Infect Dis, 92, 62-8.

Ge Y, Liu H, Qiu X, et al (2018). Genetic variants in PI3K/ Akt/mTOR pathway genes contribute to gastric cancer risk. Gene, 670, 130-5.

Ghasemi M, Vahedi Larijani L, Abediankenari S (2012). Investigation of Relationship between Hepatitis B Virus and Gastric Adenocarcinoma. Iran Red Crescent Med J, 14, 453-4.

Hosseini SM, Tabaraei B, Hadadian S, et al (2011). Increased the specificity and sensitivity of monospecific antibody against host cell protein (HCP) in quality control of hepatitis B recombinant vaccine. $J$ Paramed Sci, 2, 24-9.

Kirchner GI, Beil W, Bleck JS, et al (2011). Prevalence of Helicobacter pylori and occurrence of gastroduodenal lesions in patients with liver cirrhosis. Int J Clin Exp Med, 4, 26-31.

Lochhead P, El-Omar EM (2018). Molecular predictors of gastric neoplastic progression. Cancer Cell, 33, 9-11.

Lu T, Yang Q, Li M, et al (2018). HBV infection and extra-hepatic cancers in adolescents and 20s: A retrospective study in China. Cancer Epidemiol, 55, 149-55.

Mera RM, Bravo LE, Camargo MC, et al (2018). Dynamics of Helicobacter pylori infection as a determinant of progression of gastric precancerous lesions: 16-year follow-up of an eradication trial. Gut, 67, 1239-46.

Varga MG, Cai H, Waterboer T, et al (2018). Epstein-Barr virus antibody titers are not associated with gastric cancer risk in East Asia. Dig Dis Sci, 63, 1-8.

Wang J, Chen RC, Zheng YX, et al (2016). Helicobacter pylori infection may increase the risk of progression of chronic hepatitis B disease among the Chinese population: a meta-analysis. Int J Infect Dis, 50, 30-7.

Wei XL, Qiu MZ, Jin Y, et al (2015). Hepatitis B virus infection is associated with gastric cancer in China: an endemic area of both diseases. Br J Cancer, 112, 1283-90.

Zullo A, Romiti A, Tomao S, et al (2003). Gastric cancer prevalence in patients with liver cirrhosis. Eur J Cancer Prev, 12, 179-82.

This work is licensed under a Creative Commons AttributionNon Commercial 4.0 International License. 